\title{
Breve histórico dos cursos de Ciências Sociais da Universidade Federal de Goiás (UFG)'
}

\author{
Elias Nazareno \\ Doutor em Sociologia (Universidad de Barcelona) \\ Professor Adjunto da Universidade Federal de Goiás \\ Goiânia, Goiás, Brasil \\ eliasna@hotmail.com \\ Roberto Lima \\ Doutor em Antropologia (Universidade de Brasília) \\ Professor Adjunto da Universidade Federal de Goiás \\ Goiânia, Goiás, Brasil \\ nadanacuca@gmail.com
}

\begin{abstract}
Resumo O presente artigo tem por objetivo apresentar de forma sucinta a história e o desenvolvimento dos cursos de Ciências Sociais da Universidade Federal de Goiás (UFG) desde sua criação até hoje. Para construir esse texto, entrevistamos alguns professores com muitos anos de casa e recolhemos relatórios e memoriais de outros professores, já aposentados, que versavam sobre o curso de Ciências Sociais, além de pesquisa documental.
\end{abstract}

Palavras-chave: memória, cursos de ciências sociais, UFG.

\section{Anos 1960: gênese e formação}

$\mathrm{O}$ presente relato tem por objetivo apresentar de forma sucinta a história e desenvolvimento dos cursos de Ciências Sociais da Universidade Federal de Goiás (UFG). Por esta razão, muitas reminiscências que deveriam fazer parte deste trabalho lamentavelmente não estarão aqui literalmente apresentadas, mas com toda certeza elas compõem como fios imprescindíveis a trama que comporta toda e qualquer narrativa. Assim, seguiremos as asseverações de Benjamin, para quem, "articular historicamente o passado não significa conhecê-lo 'tal como foi'. Significa apropriar-se de uma recordação, tal como relampeja no momento de um perigo".

Claro que essa história carrega dentro de si outras, e, como não poderia deixar de ser, muitas contradições e pontos obscuros. Para construir esse texto, entrevistamos alguns professores com muitos anos de casa e recolhemos relatórios e memoriais de outros professores, já aposentados, que versavam sobre o curso de Ciências Sociais.

\footnotetext{
1. Esse texto foi originalmente redigido para uma coletânea comemorativa dos 50 anos da UFG. Por insondáveis motivos acabou não sendo publicado. Os autores agradecem aos organizadores do dossiê 50 anos do Curso de Ciências Sociais pelo interesse em publicá-lo. Agradecemos também ao professor Francisco Rabelo, que, além de conceder uma entrevista, leu uma versão anterior e corrigiu muitas falhas. As que porventura permanecem são de responsabilidade dos autores.
} 
Goiás vivia, no início dos anos 1960, a exemplo do restante do Brasil, uma conjuntura política de intensa mobilização social. Podemos destacar o movimento a favor da Reforma Agrária e a luta camponesa, Trombas, movimentos grevistas e a mobilização estudantil. Nos primeiros anos da década de 1960 o governo de Mauro Borges, fortemente influenciado pelos fundamentos do nacional desenvolvimentismo, buscava uma gestão alicerçada na construção de um estado moderno e com ações planificadas. Entretanto, mesmo com toda a movimentação política, Goiás era um estado fortemente agrário e oligárquico. Cerca de $70 \%$ da população goiana vivia no campo e a Capital, Goiânia, contava com pouco mais de 300 mil habitantes. Foi nesse contexto que se deu o movimento pela criação da UFG. Sobre isso afirma o professor Francisco Rabelo:

A estratégia da criação da UFG passava pelo projeto de desenvolvimento pela ciência (saúde, engenharia e da terra). A Faculdade de Direito já existia desde o final do século anterior e não era vista numa perspectiva de desenvolvimento de um pensamento crítico ou algo parecido, embora fosse a Faculdade de Direito o epicentro das disputas ideológicas entre direita $\mathrm{x}$ esquerda; ensino religioso $\mathrm{x}$ laico; privado $\mathrm{x}$ público. A bandeira do desenvolvimento científico e tecnológico era uma bandeira da esquerda que se associava a outras como: ensino laico e público. (Entrevista com os professores/autores, fevereiro de 2013)

É importante ressaltar que a conjuntura política à época de criação do curso de Ciências Sociais era de efervescência. O Decreto presidencial de criação da UFG veio acompanhado da pretensão, posteriormente confirmada pelas urnas em 1961, da candidatura e da eleição, como Senador por Goiás, de Juscelino Kubitschek. A proposta de criação da UFG, uma reivindicação de grupos que defendiam a educação superior laica, foi recebida com bastante reserva por parte de alguns setores da sociedade goiana. De acordo com Itami Campos (2008, p. 8),

Orlando de Castro, professor emérito, narra que, procurado para declarar apoio à criação da Universidade Federal, o professor Zoroastro Artiaga teria dito que Goiás não comportava duas universidades e que uma nova tentativa fosse feita após 50 anos.

Obviamente tal afirmação refletia o desconforto de parte da intelectualidade goiana mais próxima à igreja diante da criação da UFG, tendo em vista a fundação, poucos meses antes, da Universidade Católica de Goiás (UCG), criada em 1959. Deste modo, a criação da UFG contou, entre outras, com a oposição da Igreja Católica goiana representada pela Liga Eleitoral Católica. Apesar disso,

a criação da UFG ocorreu respeitando as áreas já existentes na Universidade de Goiás (Católica). Portanto, os cursos da antiga Faculdade de Filosofia ficaram sob o controle da Católica e os cursos de Medicina, Odontologia e Farmácia, Engenharia e o Conservatório de Música, além, é claro, da Faculdade de Direito, passam a compor a Universidade Federal. Portanto, a área de humanas - diga-se, licenciaturas - passa a ser estratégica após a criação da Universidade e a sua implantação passa a ser justificada em nome da universalização do ensino público e gratuito. (F. Rabelo, entrevista em fevereiro de 2013)

Logo após a criação da Universidade Federal de Goiás (UFG) em 1960, observou-se a necessidade de criação de um curso inovador voltado para a realidade brasileira. Norteavam essas preocupações a doutrina social de frações progressistas da igreja, a filosofia social e o ideário desenvolvimentista. Também as Ciências Sociais ainda tinham pouca visibilidade no Brasil, de forma que se optou inicialmente por outro rumo:

Assim, na ausência de uma Faculdade de Filosofia, foi criado o Centro de Estudos Brasileiros, que oferecia um curso de graduação, tendo como tema a realidade brasileira. O Centro sofreu dois golpes. O primeiro por não ter obtido autorização de funcionamento. Em vista de sua desativação iminente foi criado o curso de Ciências Sociais, junto à Faculdade de Filosofia, como alternativa para que os alunos matriculados no Centro de Estudos Brasileiros completassem a sua graduação. [O segundo golpe será discutido logo adiante] (F. Rabelo, fevereiro de 2013)

Em sua origem o curso de Ciências Sociais esteve vinculado à Faculdade de Filosofia, Ciências e Letras, que havia sido criada por meio do Decreto $n$. 51.582, de 8 de novembro de 1962. Tendo o início de suas atividades em 1963, a Faculdade foi instalada em caráter provisório e, contando com os seguintes cursos: Pedagogia; Letras Modernas e Vernáculas; Matemática e Física.

Este complexo e contraditório cenário político e social marca o nascimento do Curso de Ciências Sociais, criado em 1963 e instalado em 1964. O primeiro vestibular do curso ocorreu em fevereiro de 1964, sendo aprovados 35 alunos e as aulas foram iniciadas em março daquele ano. Imediatamente, importantes atividades acadêmicas foram levadas à frente e o Centro de Estudos Brasileiros (CEB) continuou em atividade, oferecendo cursos de extensão universitária. Entretanto, com o golpe militar de $1^{\circ}$ de abril de 
1964, parte de seus professores foram atingidos por Inquéritos Policiais Militares (IPMs) e outra parte instada a pedir demissão o que efetivou sua desativação. Também o número de alunos matriculados seria, imediatamente após o golpe, reduzido a 15. As razões para a forte evasão explicam-se, em parte, pela tentativa de uma parcela do corpo discente de se resguardar de possíveis perseguições políticas. O relato do professor aposentado da Faculdade de Ciências Sociais e aluno da primeira turma do curso, Itami Campos, registra:

Em março de 1964, muitos alunos do Curso de Ciências Sociais integravam as equipes que estavam sendo formadas para iniciar o programa de alfabetização sob orientação de Paulo Freire, em convênio com a Secretaria de Estado da Educação. Coincidentemente, em $1^{\circ}$. de abril de 1964, o professor Paulo Freire era esperado em Goiânia para completar a formação dos alfabetizadores e dar início ao programa. Teve que fugir para não ser preso.

A conjuntura política, que de algum modo era favorável à movimentação e ao debate político, é radicalmente modificada com a implantação do regime de exceção. O CEB foi invadido e fechado, tendo seu acervo confiscado; professores e alunos foram afastados e presos. O reitor da UFG, Colemar Natal e Silva foi afastado em 1964, sendo designado pelo regime militar um novo Reitor pro tempore, José Martins D'Alvarez, que, mesmo indicado temporariamente, seria Reitor de 1965 a 1968.

No início, a Faculdade e o curso não tinham sede própria, de acordo com o que afirma Itami Campos (2008, p. 6):

O curso de Ciências Sociais peregrinou funcionando cada ano em um local: iniciou em 1964 em sala da Faculdade de Engenharia (Setor Universitário); no segundo ano, foi deslocado para salas do Instituto Histórico e Geográfico de Goiás (IHGG) (Rua 82, Praça Cívica); em 1966, foi para um prédio, alugado, na Rua 15 com a Rua 20; e, em 1967, para salas da Faculdade de Economia e Administração da UCG (Setor Universitário). Em 1968, a Faculdade foi instalada em prédio, dito próprio, no Campus da UFG, no Setor Universitário (hoje, sede da Faculdade de Educação).

Outros dois tipos de precariedade também marcaram o início do curso: não havia uma grade curricular definida, a bibliografia era praticamente inexistente na área de Ciências Sociais; e o quadro de professores era composto por juristas e autodidatas em áreas afins à Antropologia, à Ciência Política e à Sociologia.

Essa é uma questão curiosa. Aparentemente, ou seja, no papel, os proponentes do curso afirmavam tê-lo originalmente pensado a partir da matriz curricular do curso de Ciências Sociais da Universidade Federal do Ceará (UFC), com forte predominância da área de Antropologia. Isso foi uma clara tentativa de aproximá-lo das matrizes vinculadas às Ciências Sociais. Contudo, as dificuldades em compor um quadro de docentes com formação na área de Ciências Sociais, além da clara resistência dos professores da Faculdade de Direito, acabaram levando o processo em outra direção. Quando não estavam ligados à área jurídica, os professores eram profissionais, em sua maioria, autodidatas em Sociologia ou Antropologia, como foi o caso do professor Teodoro da Silva Neiva, autodidata em antropologia. Claro que não é possível generalizar desde o princípio o curso contou com a colaboração de alguns professores muito competentes, como o professor Lauro Campos, que fez concurso para catedrático em Economia Política na UFG em 1963, onde lecionou também História do Pensamento Econômico. Em 1966, Lauro Campos ingressa na UnB como professor. Outro professor que colaborou com o curso até o final dos anos 1970 foi o padre José Pereira de Maria, que seria depois Reitor da Universidade Católica de Goiás de 1979 até 1984.

Mas o interessante é que houve um vácuo em relação à gestão acadêmica do curso, e esse vácuo foi preenchido pelos alunos. Sobre essa questão afirma Itami Campos:

Talvez devido a essa condição, os alunos da $1^{\text {a }}$ turma assumiram a estruturação do curso, inclusive sugerindo ao final de cada ano a reforma da grade curricular por eles cursada. Essa movimentação é assumida e liderada também por alunos de turmas posteriores, pois em 1965 o "colegiado de alunos" do Curso cria o Centro de Estudos Sociais e Políticos (CESP), órgão representativo dos alunos. O CESP promoveu muitos encontros, debates e discussões. A sua atuação, considerada subversiva, fez com que, em 1969, sua sede na UFG fosse invadida por agentes da repressão (do SNI). Na invasão do CESP, sequestram documentos e livros (da iniciante biblioteca), sendo proibido o seu funcionamento a partir de então. (2008, p. 4)

Mesmo diante da resistência imposta pela nova realidade, os poucos alunos que restaram no curso tentaram continuar com sua mobilização. No intuito de promover melhoras no curso buscaram uma aproximação com os cursos de Sociologia e Ciências Sociais da Universidade de São Paulo (USP), da Universidade Federal de Minas Gerais (UFMG) e da Universidade de Brasília (UnB). Por meio do CESP foram promovidos, entre os anos de 1965 e 1968, alguns debates, com a presença de importantes intelectuais brasileiros como Florestan Fernandes, "afastado sob aposentadoria compulsória, com vencimentos 
proporcionais ao tempo de serviço, em 24/4/1969, por aplicação do Ato Institucional n. 5 pela ditadura militar" (Sacchetta, 1995, p. 56).

Ainda segundo Itami Campos, os alunos foram responsáveis diretos pela estruturação curricular do curso de Ciências Sociais, buscando alterar a matriz curricular na tentativa de aproximá-la do que seria suas bases epistemológicas. Esta interessante iniciativa seria desmontada em 1968, a partir da segunda turma do curso (a primeira havia colado grau em 1967), com o processo de perseguição às principais lideranças do movimento estudantil e com a tomada por parte do regime militar do controle administrativo e acadêmico da universidade. O regime indicava os professores e, consequentemente, o conteúdo a ser ministrado em cada disciplina era fortemente controlado.

De forma extremamente prematura, apenas quatro anos depois de sua criação, a UFG deixa de ser um espaço vivo de discussão e inovação acadêmica e passa a viver sob a tutela da intolerância e da perseguição. O professor Sergio Paulo Moreyra (2008, p. 33), professor aposentado da Faculdade de Ciências Humanas e Filosofia, em relação ao período posterior ao golpe, afirma:

Os anos seguintes foram marcados por dolorosas amputações humanas e institucionais, que reduziram a UFG a uma existência convencional e subordinada. Foi um tempo marcado por demissões arbitrárias de professores e técnicos; prisão de servidores, alunos e professores; fechamento de cursos; instauração da censura ideológica e o pior de todos os males trazidos pela ditadura: a delação, o "dedurismo", o poder da denúncia ideológica, a acusação gratuita com prova ou sem prova. Proliferou em toda a universidade, destruiu carreiras brilhantes, abriu oportunidades injustificadas para colaboradores medíocres do governo militar.

A fraca vinculação com a realidade local, a tímida relação com o campo das Ciências Sociais e a debilidade em termos de formação dos professores, fez com que em 1968, como vimos anteriormente, parte dos professores fosse afastada.

O clima de tensão aumenta, sobretudo a partir da realização de uma assembleia organizada pelos alunos que exigiram, além da saída dos professores do curso vinculados ao Direito e que priorizavam apenas aqueles conteúdos vinculados à Teoria Geral do Estado, a adoção por parte dos professores de uma bibliografia verdadeiramente voltada para as Ciências Sociais. Autores como Florestan Fernandes, Caio Prado Jr., Fernando Henrique Cardoso, Celso Furtado, eram vistos apenas em círculos de leitura e debates internos organizados pelos próprios alunos.

Em dezembro de 1968, os poucos espaços restantes para a movimentação política são irremediavelmente fechados por força do Ato Institucional número 5 (AI-5) de 13 de dezembro. Em relação à Universidade, três dias depois de emitido o AI-5, foi emitido também o Decreto n. 63.817, a Reforma Universitária de 16 de dezembro de 1968, que aprovou o Plano de Reestruturação da Universidade. Esta traria uma série de mudanças que afetariam profundamente a vida dos estudantes e professores universitários. Os campi são afastados dos centros urbanos, é criado o sistema de créditos, são criados os Institutos Básicos e os Departamentos são organizados por área de conhecimento, assim como os colegiados de cada curso.

A Faculdade de Filosofia, Ciências e Letras é desmembrada em quatro unidades: o Instituto de Ciências Humanas e Letras (ICHL), o Instituto de Matemática e Física (IMF), o Instituto de Química e Geociências (IQG), e a Faculdade de Educação. O ICHL foi finalmente inaugurado em 1969. Ficou temporariamente no mesmo prédio da Faculdade de Educação, sendo depois transferido para o Seminário Santa Cruz na Vila Pedroso, local de difícil acesso para os estudantes. Em 1969, foi transferido para a Faculdade de Agronomia e Veterinária, sendo deslocado no início dos anos 1970 para o Campus II, local no qual após a construção dos prédios em 1974 seus departamentos foram definitivamente instalados. De acordo com Rabelo,

no prédio da faculdade de filosofia ficaram o ICHL e a FE. Em 1970, o prédio, por ser de construção recente, passou a ser destinado também à área básica, assim como a Faculdade de Direito. Os dois prédios foram interditados, pois o excesso de peso provocou problemas na estrutura. Ficamos um período sem aulas e, posteriormente, as turmas foram redistribuídas por prédios da Escola de Engenharia, UCG e Seminário Santa Cruz, o que ocorreu no $1^{\circ}$ semestre de 1972. No $2^{\circ}$ semestre, fomos para a Escola de Agronomia e, depois, ficaram prontos alguns prédios do campus II (1974) e o ICHL veio para o prédio que, posteriormente, foi passado ao IMF. Concluídos os dois prédios (hoje FACOMB e da FCS, FH e FAFIL em 1976) lá se instalou o ICHL. (F. Rabelo, entrevista, fevereiro de 2013) ${ }^{2}$

Os conteúdos teóricos e metodológicos apenas são aplicados após passar pelo crivo da censura, como observa Rabelo:

2. Há uma disparidade nas afirmações feitas pelos entrevistados e presentes nos artigos memoriográficos consultados sobre a data de instalação definitiva, entre julho de 1973 (para Lena Castelo Branco Ferreira de Freitas s/d) e 1976. Embora correndo o risco de estar reproduzindo um equívoco nas datas estamos mantendo o relato de Rabelo por ser o mais detalhado no que se refere ao périplo da faculdade em busca de sua sede. 
Para dar aulas, precisávamos de um atestado ideológico emitido pela Secretaria de Segurança Pública (SSP) [...] Um outro aspecto que deve ser considerado relaciona-se com a limpeza ideológica feita na biblioteca, que era, naquele momento, muito precária. Mas líamos Caio Prado, Nelson Werneck Sodré e outros mais ligados à esquerda. De Marx, nos restou a coletânea de textos organizada por Bottomore e publicada pela Zahar. (F. Rabelo, entrevista, fevereiro de 2013)

Mesmo diante deste clima de instabilidade e arbitrariedade, os estudantes organizados ou não procuram participar dos fóruns deliberativos da Universidade como os Conselhos Superiores, Câmaras Setoriais, Colegiados de Cursos e Congregações de Unidades, tentando assim influenciar de algum modo nos assuntos e decisões que diziam respeito ao curso. Certamente essa participação era marcada pela oposição entre direita e esquerda, e também as mudanças no quadro de professores tinham a ver com isso. Se, por um lado houve o afastamento dos professores do Direito, também professores mais próximos à esquerda foram afastados por motivos aparentemente acadêmicos e relacionados ao seu desempenho como professor em sala de aula. Entretanto, relata Rabelo:

Em 69, logo de início, ocorreu a saída do Professor de Geografia Humana, e o professor de História Econômica, Política e Social (Geral), Prof. Juarez Costa Barbosa, foi substituído por pressão de parte da turma. A motivação não era política, mas acabou sendo embalada como tal e, hoje, diria que a embalagem era, de fato, política, mas não partiu dos órgãos de segurança, mas do conservadorismo de boa parte da turma. (Rabelo, entrevista, fevereiro de 2013)

Os anos 1960 representaram em seu início um mundo de possibilidades desde a perspectiva da participação política, que como vimos refletia uma intensa mobilização por parte dos setores organizados da sociedade civil brasileira. A eclosão do regime de exceção promoverá uma quebra nesse processo. A ditadura, apesar da aparente desorganização em seus primórdios (1964 até 1967), fato que possibilitou a organização de alguma resistência por parte dos estudantes, não tardaria em mostrar sua face mais autoritária por meio dos Atos Institucionais, sobretudo o AI-5, que demonstrava claramente as intenções do Regime Militar de não mais fazer concessões a qualquer tipo de reivindicação ou de desobediência civil. No final dos anos 1960, a sociedade brasileira, com raríssimas exceções, assistia à consolidação da ditadura militar, e o foco de resistência universitária era duramente atingido pela Reforma Universitária. ${ }^{3}$

\section{Anos 1970: a consolidação do Curso de Ciências Sociais e a repressão}

Os anos 1970 são marcados por duas questões: o início do processo de profissionalização do curso de Ciências Sociais, assim como dos demais cursos da UFG; e a repressão do regime militar. Sobre a primeira questão, aponta Rabelo que

o curso toma um novo rumo com a conclusão das primeiras turmas e a incorporação de alguns deles como professores, além da presença das professoras Maria Luíza Centeno, formada na ELSP-SP, Octávia Fernandes (MG), Adelaide Baêta (MG) e do Prof. Carlos Rodrigues Brandão, Psicologia Social (PUC-RJ). Nesse momento, retorna de Paris, o Prof. Pe. José Pereira de Maria, onde havia concluído o seu doutorado em Antropologia. Esse grupo, de fato, fez a diferença tanto no que diz respeito ao treinamento para a pesquisa quanto para o engajamento político. As aulas do Pe. Pereira, assim como da Profa. Ana Lúcia da Silva (historiadora que havia feito pós-graduação no Chile) e da Profa. Maria Alice Lima Gomes de Menezes eram, além de competentes, muito politizadas. (Entrevista, fevereiro de 2013)

Grande parte dos professores vinculados ao ICHL saem do estado de Goiás para a realização de cursos de mestrado. Este foi o caso do professor Itami Campos, que realizou seu mestrado em Ciência Política na UFMG, a partir de 1969; do professor Francisco Chagas Evangelista Rabelo, que realizou o mestrado também na UFMG (1974-1976), do professor Sérgio Paulo Moreyra, da professora Maria Alice Lima Gomes de Menezes (1972-1973) entre outros. Foi neste período também, mais precisamente em 1972, que foram criados os programas de Mestrado em Ciências Humanas (que posteriormente virou Mestrado em História) e Mestrado em Letras. Assim, parte do corpo docente das Ciências Sociais ingressaria no mestrado em Ciências Humanas, que tinha originalmente como área de concentração Sociologia, História e Antropologia e, em 1978, passa a ter área de concentração em História das Sociedades Agrárias. ${ }^{4}$

3. Sobre a Reforma Universitária de 1968, ver Martins (2009).

4. Em sua entrevista, Rabelo descreve assim a mudança da área de concentração: - Fazia eu parte do Programa, embora tivesse apenas o mestrado (naquela época podia) e fomos reformular a grade curricular. O colegiado se dividia entre conservadores e renovadores (há 35 anos atrás, eu tinha apenas 30 anos). Os renovadores: Dalísia E. M. Doles, Janaína Amado e eu (éramos absolutamente minoritários e pouco 
Em 1970 fundou-se o Museu Antropológico (MA/UFG), que se constituiu como órgão suplementar da Universidade, vinculado à Pró-Reitoria de Pesquisa e Pós-graduação. De acordo com Edna Luísa de Melo Taveira (2012, p. 1), Diretora aposentada do Museu Antropológico/UFG,

o Museu Antropológico da Universidade Federal de Goiás foi idealizado pelos professores Acary de Passos Oliveira, Antônio Theodoro da Silva Neiva, Vivaldo Vieira, Pe. José Pereira de Maria e Pe. Xavier Enciso, quando, em 1969, realizaram pesquisa de campo no Parque Nacional do Xingu.

A implantação do Museu foi inciativa dos professores do antigo Departamento de Antropologia e Sociologia, do Instituto de Ciências Humanas e Letras da UFG, que hoje integra a Faculdade de Ciências Sociais.

Como ocorreu com outros órgãos da UFG, o Museu, ainda segundo Taveira (2012), funcionou em diferentes locais por alguns anos. O primeiro foi uma sala da atual Faculdade de Educação, permanecendo neste local até 1970. Depois, foi transferido para o prédio da Escola de Enfermagem. "Nesse local foram realizadas as primeiras pesquisas nas áreas de Etnologia e Arqueologia, sendo que o acervo vinha se constituindo desde o início de sua criação, sobretudo, após as primeiras viagens ao Xingu e à Ilha do Bananal, no Rio Araguaia” (p. 1).

Vale ressaltar que, se institucionalmente a UFG estava sendo organizada de forma mais efetiva, desde a perspectiva política a ditadura não dava trégua. Deste modo, a segunda questão marcante dos anos 1970, a repressão, era mais que uma sombra sempre presente:

A turma de 69 era muito politizada. Alguns foram presos e outros se exilaram voluntariamente no exterior. Dos que foram presos, foi marcante a declaração de um deles, em horário nobre de TV, renunciando à militância e à luta armada. Éramos, a todo o momento, surpreendidos com a prisão de pessoas muito próximas a nós, e a convivência com o terror não era nada agradável. Em 77, para ser contratado pela UFG, precisei de uma autorização da ASI (todos precisavam), que não me foi concedida, porque ligaram o meu sobrenome ao do militante político exilado, José Maria Rabelo. (Rabelo, entrevista, fevereiro de 2013)
Na conjuntura daqueles anos, o elevado nível de controle do regime em relação à contratação dos professores e à mobilização da sociedade civil começa a conviver com a promessa nunca cumprida de redemocratização, com o nome de abertura (muito apertada dirão muitos) a partir da metade da década de 1970 . Esta abertura foi em parte promovida pelo próprio regime e ficou conhecida como "abertura lenta, gradual e segura" durante o governo do General Geisel, mas em grande parte foi resultado das mobilizações sociais que ocorrem a partir de 1978, como os movimentos grevistas do ABC paulista, a luta pela anistia ampla, geral e irrestrita e a reorganização partidária.

$\mathrm{Na}$ onda do processo de abertura, ocorre a mobilização nacional dos docentes que reivindicam a adoção de uma política clara em termos de plano de cargos e salários. Em 18 de dezembro de 1978 é criada a Associação dos Professores da UFG (ADUFG) como parte de uma estratégia para a fundação de um sindicato nacional que veio a nascer em 1981 (a ANDES).

Obviamente as universidades não ficariam alheias a todo este processo de mobilização política. Na UFG há uma forte pressão pela democratização dos espaços acadêmicos, como o Conselho Universitário e também a exigência do fim das listas sêxtuplas para a escolha dos reitores e a adoção das listas tríplices. Grande parte dos professores do Curso de Ciências Sociais se engaja na luta pela redemocratização.

\section{Anos 1980: década economicamente perdida, década politicamente aproveitada}

Em 6 de novembro de 1980, Goiânia foi o palco de um acontecimento histórico:

\begin{abstract}
Surpreendentemente, o Instituto de Física da UFG, sozinho, em plena ditadura militar, declara-se em greve geral por tempo indeterminado. Essa ousadia estourou como uma bomba nacionalmente. Imediatamente outros institutos da UFG também se declararam em greve e esta se espalhou por todo o Brasil. Foi a primeira greve nacional de uma categoria. (Ana Lucia da Silva. Carta enviada aos professores do IF. Goiânia 24 de agosto de 2012)
\end{abstract} dificuldade dessa objetivação, e aventou uma saída em termos de Sociedades Agrárias. Terminada a fala, uma pessoa do nosso grupo começa a tecer loas à ideia do Prof. Palacín, já transformada em proposta. Eu nada entendia, até que essa pessoa chegou pra mim e me disse qual era a manobra. Começamos então falas elogiando a proposta. Entre temeroso e envaidecido, o Prof. Palacín acabou assumindo o filho, algo muito raro, tratando-se de um padre estrangeiro, e seus seguidores também, e a área de concentração foi aprovada. Se não foi por unanimidade, foi quase. 
No início dos anos 1980 é eleito como Reitor o professor Joel Pimentel de Ulhoa, que buscará a reorganização administrativa e acadêmica da UFG. Foi um período que coincide com a reorganização do movimento sindical brasileiro e que foi marcado por greves dos professores universitários em quase todos os anos da década. A criação da Andes no começo da década, em 1981, seria de enorme importância para a condução dos movimentos grevistas.

Assim, o processo de luta pela democracia, que se inicia no fim da década anterior, consolidar-se-á na seguinte:

Ao final dos anos 70, o engajamento no processo de redemocratização foi generalizado por parte de professores e alunos do curso de ciências sociais. Se durante o período mais forte da repressão a divisão era entre e esquerda e direita, neste momento ela se instaura dentro da esquerda, uns se filiando às correntes que se satisfaziam com a democracia representativa e outros buscando formas mais efetivas de democratização da sociedade. Essa ebulição vai consolidar-se, em termos partidários, entre (P)MDB e PT, logo depois. Do ponto de vista acadêmico, não houve maiores mudanças, a não ser na crítica feroz ao modelo de desenvolvimento e na adoção de textos que davam voz aos movimentos sociais. (Rabelo, entrevista, fevereiro de 2013)

Dentro da política acadêmica uma série de mudanças ocorre e para os professores e alunos será importante o modo como ocorrem, ou seja, como um debate. No início dos anos 1980 o regime de crédito é questionado ocorrendo a volta ao regime seriado; desaparecem os colegiados de curso e os Departamentos tornam-se responsáveis pelo ensino. Os currículos são reformulados e o curso de Ciências Sociais reformula sua grade curricular tendo por base os clássicos da Antropologia, da Sociologia e da Ciência Política. Além da reformulação curricular, os departamentos retomam a condução dos assuntos acadêmicos, assim como a rearticulação das áreas para formulação de projetos conjuntos de maior envergadura:

O processo de redemocratização atingiu de cheio a Universidade e, particularmente, o curso de Ciências Sociais. $\mathrm{O}$ debate não se limitou à redemocratização da sociedade em geral, mas também da universidade e do conhecimento por ela produzido e transmitido, chegando até suas instâncias universitárias básicas: departamentos, cursos, currículos e colegiados. Em nível de UFG, foi discutido e aprovado um novo Estatuto e, no curso de Ciências Sociais, foi discutido e aprovado um novo currículo a partir de duas propostas: uma de caráter mais profissionalizante e uma outra de caráter mais acadêmico e de teor crí- tico. Aprovada a segunda proposta em reunião colegiada, toda a sua elaboração foi objeto de discussão e, posteriormente, aprovada e encaminhada à Câmara de Graduação. Outro momento significativo para o curso foi a discussão que levou à formulação de um projeto de pesquisa amplo, incluindo todas as áreas e envolvendo os alunos daquele período (1987 a 1990). Encaminhado ao CNPq, ele foi financiado e executado com sucesso. (Rabelo, entrevista, fevereiro de 2013)

Em 1982 o Museu é reestruturado, sendo definido como centro de pesquisa interdisciplinar, cujo objetivo fundamental seria a pesquisa antropológica, mantendo-se aberto para vincular-se a outros departamentos e unidades da UFG. Desde essa época o museu se torna órgão suplementar (hoje vinculado à Pró-Reitoria de Pesquisa e Pós-Graduação):

A finalidade essencial foi estudar o modo de vida do homem na região Centro-Oeste, estabelecer a necessidade de pesquisa e organizar o acervo decorrente da mesma, implementando atividades de caráter dinâmico, investigativo e pedagógico. (Taveira, 2012, p. 2)

A partir de 1987, o Departamento de Ciências Sociais e o Museu passaram a oferecer regularmente, além do curso de graduação em Ciências Sociais, cursos de especialização e atualização em planejamento social, políticas públicas, economia agrícola, antropologia social, museologia, arqueologia, linguística, etnologia e história da África. Alguns professores atuais da Faculdade tiveram nestes cursos sua primeira especialização na área em que iriam-se profissionalizar, como a profa. Cintya Rodrigues, que foi aluna da primeira turma de especialização em antropologia social.

Foi também um período em que o processo de qualificação docente ganhou novo impulso com diversos professores saindo em busca da realização de seus respectivos mestrados e doutorados. Em meados da década foi discutido e aprovado o Plano Departamental que estabelecia como prioridade a saída de professores para doutoramento. Cerca de 15 professores se afastaram entre 1988 e 1999 e, destes, 13 completaram seus doutorados.

\section{Anos 1990: neoliberalismo, avaliações e sucateamento}

Infelizmente o final da década de 1980 seria marcado pela ascensão das políticas neoliberais vinculadas ao que ficou conhecido como "Consenso de 
Washington". ${ }^{5}$ O Governo de Fernando Collor de Mello (1990-1992) iniciou um processo de desmonte do Estado brasileiro e as Universidades brasileiras passaram por um intenso processo de sucateamento. Os servidores públicos federais foram incentivados por meio dos Planos de Demissão Voluntária (PDVs) a deixarem seus postos de trabalho.

$\mathrm{Na}$ esteira do sucessor imediato de Fenando Collor, o Vice-Presidente Itamar Franco deu continuidade às políticas neoliberais. Seu sucessor Fernando Henrique Cardoso, por meio das políticas adotadas por seu Ministro da Educação, Paulo Renato, iniciou um impressionante processo de expansão do ensino universitário privado brasileiro. A política de baixos salários nas Universidades públicas, aliada à expansão das empresas de educação, fez com que um número significativo de professores das Universidades públicas fosse deslocado para aquelas empresas em busca de melhores condições de trabalho e melhores salários. A esse processo de desmonte se aliaram os já citados PDVs e a proibição de concursos públicos, de forma que as vagas que surgiam por demissões e aposentadorias não voltavam a ser preenchidas. Assim, o processo de precarização do ensino público se acentuou ainda mais, ocorrendo um enorme desestímulo às atividades de ensino e pesquisa:

Foi um período muito difícil para Universidade e muitos professores tiveram dificuldade de manter o padrão de vida que levavam. A escassez de tudo (professores, funcionários e de infraestrutura para sala de aula) colocou a universidade pública na retaguarda de um processo que, desde os anos 60, tinha se colocado à frente. Além do mais, a desmobilização política afetou também a vida universitária como um todo. (Rabelo, fevereiro de 2013)

Como parte das estratégias para um "Estado Mínimo" e para a transformação do Estado, de uma estrutura que planeja e investe, em um Estado que apenas gerencia o capital, além do arrocho salarial e da ausência de vagas, foi criada uma série de políticas de avaliação do setor público e concessionado. Assim, foi a partir da gestão de Paulo Renato à frente do Ministério da Educação que surgem as políticas de avaliação das instituições públicas e privadas e de seus respectivos cursos de graduação.

Quanto ao tipo de avaliação implantado no Brasil, considero-a como fundamentalmente coercitiva e, portanto, dominantemente controladora. Em vez de promover a qualidade, como é desejável, ela tem padronizado por baixo. Além da padronização que os currículos mínimos já promoviam, agora também padroniza o conteúdo, descaracterizando possíveis iniciativas locais. (Rabelo, fevereiro de 2013)

Um dos resultados curiosos desta política foi que as exigências em relação ao nível de formação dos professores passam a ser muito mais estritas. Neste sentido, o número de professores com doutorado no país cresce de forma vertiginosa entre os anos de 1990 e 2000. Mas principalmente cresceu o número de doutores que não conseguiam emprego nas universidades simplesmente porque não havia concurso.

Em 1992 começa a ser desenvolvida a especialização em Políticas Públicas, que veio a se tornar a principal pós-graduação lato sensu do Departamento de Ciências Sociais. Essa especialização, em um primeiro momento, teve uma importância muito grande no sentido profissionalizante, pois ainda não havia a pós-graduação strictu senso em ciências sociais. Por outro lado a especialização teve (e tem) grande importância na profissionalização e capacitação dos funcionários públicos em Goiás.

No ano de 1998 foi publicado o primeiro número da revista Sociedade e Cultura, revista interdisciplinar de ciências sociais, que tem como missão "publicar estudos sobre temas das Ciências Sociais e Humanidades, contribuindo para o debate de ideias em âmbito nacional e internacional".

Em 1999, 30 anos após a criação dos mestrados em Ciências Humanas (História) e em Letras, foi criado o Mestrado Acadêmico em Sociologia no Departamento de Ciências Sociais. Ao ser criado, esse mestrado, Área de Concentração em "Sociedade e região", integrou a quase totalidade de professores doutores do então departamento (doutores em Sociologia, em Antropologia e em Ciência Política). Com a criação desse mestrado a revista Sociedade $e$ Cultura passa a ser ligada a ele, sem perder a ênfase interdisciplinar.

\section{Anos 2000: milênio novo, desafios novos e problemas nem tanto}

Os anos 2000 começam como terminaram os anos 1990. A eleição de Lula em 2002 não veio a concretizar a ruptura que se esperava com o modelo desenvolvimentista até então implementado no Brasil. Embora questões sociais tenham entrado na pauta de discussão, elas não alcançaram a proeminência que setores mais à esquerda que o apoiaram esperavam.

5. Sobre o "Consenso de Washington" ver: Béjar, Ramón Casilda. América Latina y el Consenso de Washington. Boletín económico de ice n. 2803 del 26 de abril al 2 de mayo de 2004. 
Na FCHF, em 2001, a licenciatura em ciências sociais desvincula-se do bacharelado em Ciências Sociais pela percepção da necessidade de formar quadros profissionais para atuar na docência das ciências sociais no ensino médio e inicia-se uma discussão que perdura até hoje sobre a inserção de do cientista social como professor de sociologia, disciplina obrigatória no ensino médio.

No ano seguinte, Custódia Selma Sena e Nei Clara de Lima, antropólogas da UFG, elaboram a concepção teórica da atual exposição de longa duração do Museu Antropológico. A exposição "Lavras e Louvores" foi resultado da pesquisa e reflexão sobre a região imaginada sertão. A exposição apresenta uma leitura singular da região Centro-Oeste, que rompe com a historiografia evolucionista tradicional sobre esta, foi inaugurada em 2006 quando da realização em Goiânia da $25^{a}$ Reunião Brasileira de Antropologia.

Em 2007 teve início o curso de Licenciatura Intercultural Indígena, que, embora sediado na $\mathrm{Fa}-$ culdade de Letras, contou com participação ativa do corpo de antropólogos e sociólogos da UFG. Voltado para a qualificação de professores indígenas da bacia Araguaia-Tocantins, esse curso tem importância nacional por seu caráter multidisciplinar inovador e por trazer saberes outros à universidade.

Em meados da primeira década do milênio as Universidades públicas brasileiras conseguem sair do ciclo de sucateamento herdado do governo FHC por meio do REUNI (Decreto n. 6.096 de 24 de abril de 2007). O REUNI foi percebido por alguns segmentos dos professores como o aprofundamento das reformas da educação superior nos moldes sugeridos pelo Banco Mundial. Contudo, era também a única possibilidade que havia naquele momento para romper o ciclo de diminuição de quadros efetivos e para a abertura de novas áreas de pesquisa, de forma que, dentro de um debate bastante acalorado e marcado por controvérsias, a universidade aceitou o desafio (chamado por muitos de chantagem) e a FCHF apresentou uma proposta que incluía cursos novos e ampliação do número de vagas nos cursos existentes. O número de vagas oferecidas nos cursos de graduação foi ampliado (em proporção muito maior que o número de vagas para docentes, diga-se de passagem) e os recursos públicos para o financiamento de pesquisas foram parcialmente recompostos.

Os docentes do curso de ciências sociais empenharam-se em elaborar uma proposta de criação de dois novos cursos (o curso de ciências sociais noturno com habilitação em políticas públicas e o curso de museologia). Essas propostas, apresentadas junto ao projeto da FCHF, foram aprovadas na íntegra. Nos anos seguintes começou tanto a contratação dos novos professores quanto a implantação dos cursos.
Ainda no ano de 2007, professores e alunos do departamento de ciências sociais foram centrais na elaboração e posterior aprovação do projeto UFGInclui, que instituiu cotas para estudantes de escola pública e estudantes negros oriundos de escola pública. A aprovação foi marcada por debates muitas vezes acirrados em que professores, funcionários e alunos de várias faculdades envolveram-se (Alex Ratts do Instituto de Estudos Socioambientais (IESA), Angelita Pereira de Lima da Facomb, Joana Plaza da Faculdade de Letras (FL), Osni Silva Nelson Cardoso e Bryon Hall do Instituto de Matemática (IME), Eulange Sousa do Hospital das Clínicas (HC), Geovana Reis, entre vários outros). Os professores Roberto Lima e Joaze Bernardino do Departamento de Ciências Sociais foram escolhidos pelos diversos coletivos da UFG interessados em uma real política de ações afirmativas na Universidade para elaborarem um projeto a ser apresentado à Câmara de Graduação. Esse projeto veio a ser apresentado e defendido pela primeira vez na Câmara por Cintya Rodrigues, à época chefe do DCS. Há que se ressaltar a atuação das alunas dos coletivos do movimento negro dentro da Universidade, que conseguiram ocupar lugares estratégicos nas diversas instâncias deliberativas da UFG e participaram ativamente dos debates e da aprovação, que se deu em 30 de junho de 2008.

No ano de 2008 foi aprovado e em 2009 começou a funcionar o Mestrado Acadêmico em Antropologia, com Área de Concentração em Antropologia, a partir de um esforço de todos os professores dessa área, mas, principalmente, da profa. Custódia Selma Sena, que veio a ser, depois, a primeira coordenadora do curso.

A implantação do Programa de Mestrado acadêmico em Antropologia Social, na Universidade Federal de Goiás (UFG) pretende intensificar a produção antropológica já em desenvolvimento no (à época) Departamento de Ciências Sociais e no Museu Antropológico.

O objetivo mais geral do Programa proposto é oferecer a seus alunos uma formação acadêmica sólida que garanta uma competência científica e profissional em Antropologia, através da criação de um ambiente de práticas e de discussão teóricas que consolidem as linhas de pesquisa já delineadas e abra possibilidades para as emergentes.

2009 foi um ano bastante agitado para as ciências sociais na UFG. A FCHF foi desmembrada em três faculdades: a Faculdade de Ciências Sociais, a Faculdade de Filosofia e a Faculdade de História. Além disso, começam a ser implantados os cursos resultantes do Reuni: o curso de Ciências Sociais noturno com habilitação em Políticas Públicas e o curso de Museologia.

O curso de Ciências Sociais, noturno, com habilitação em Políticas Públicas, é voltado para a forma- 
ção de profissionais capacitados para atuar nas áreas de formulação, gestão e avaliação de políticas públicas; já o curso de Museologia visa cobrir uma lacuna na formação de profissionais na área museológica. Pelos dados do Instituto do Patrimônio Histórico e Artístico Nacional (IPHAN), em 2009 não havia nenhum curso de museologia nas regiões Centro-Oeste e Norte (ver Nei Clara de Lima et al., 2009).

$\mathrm{O}$ ano de 2010 marcou o nascimento do primeiro doutorado da Faculdade, o doutorado em Sociologia, como decorrência da proposta do mestrado; que havia sido implementado em 1999 contou com uma mudança na área de concentração, que se torna mais ampla e ambiciosa: "Sociedade, política e cultura".

Em 2011 foi aprovado o mestrado em Ciência Política, que começou a funcionar em 2012, já com nota 4 na CAPES:

As justificativas para a criação de um programa de pós-graduação em Ciência Política na UFG se ancoram em dois eixos principais: o institucional, resultado da evolução da própria área de Ciências Sociais na instituição, e o regional, relacionado à baixa oferta de programas na região Centro-Oeste e à crescente demanda por formação mais qualificada.

Aproveitando-se de um quadro docente enxuto e com qualificação específica em Ciência Política, o PPGCP/UFG se organiza em uma única área de concentração, "Estado, Comportamento Político e Instituições", que abrange uma gama ampla de campos de investigação e possibilita que todas as especializações dos professores do Programa, (permanentes e colaboradores) estejam contempladas. Disponível em: <http://cienciapolitica.cienciassociais.ufg.br/pages/37712>.

Deve-se salientar que, com a criação desses dois programas de pós-graduação, a revista Sociedade $e$
Cultura passou a ser ligada aos três programas de pós-graduação da Faculdade de Ciências Sociais. Hoje a revista conta com classificação Qualis A2 em Antropologia/Arqueologia, B1 em interdisciplinar e em Sociologia e B2 em Ciência Política.

Em 2012, com a participação, além da Faculdade de Ciências Sociais, das Faculdades de História, Ciências Econômicas, Direito e Letras, foi criado o curso de Relações Internacionais. O primeiro vestibular ocorreu no início de 2013.

Finalmente, em 2013, o Mestrado em antropologia social foi promovido para Quallis 4 na CAPES, o que mobilizou seus professores para a imediata criação de um curso de doutorado, que foi aprovado em 2014 e já está sendo implementado.

Todo esse esforço, em que se juntam ensino, pesquisa e extensão, é levado adiante por um corpo docente renovado (com alguma instabilidade ainda, devida aos óbvios ajustes que são necessários a essa expansão), formado atualmente por 57 professores. Destes, 54 (95\%) são doutores, 1 (2\%) são doutorandos e $2(3 \%)$ são mestres.

E assim chegamos onde estamos. Atualmente a Faculdade de Ciências Sociais tem um curso bem consolidado de Ciências Sociais, bacharelado e licenciatura, que inclusive ganhou nota máxima no Exame Nacional de Desempenho de Estudantes (Enade), 2012 e cinco estrelas no Guia do Estudante; busca consolidar o curso de Museologia, a habilitação em Políticas Públicas e o curso de Relações Internacionais; possui ainda três programas de pós-graduação strictu senso, Sociologia - com mestrado e doutorado -, Antropologia - com mestrado e doutorado - e Ciência Política - com mestrado; uma revista, a Sociedade e Cultura, avaliada como A2 - Antropologia/ Arqueologia - e B1 - multidisciplinar e sociologia -; um quadro docente renovado; e, muito trabalho pela frente.

\section{Referências}

BÉJAR, R. C. América Latina y el Consenso de Washington. Boletín Económico de Ice, n. 2803, del 26 de abril al 2 de mayo de 2004.

BENJAMIN, W. Sobre o conceito da história. In: Obras escolhidas: magia e técnica, arte e política. Tradução de Sergio Paulo Rouanet. São Paulo: Brasiliense, 1986, v. 1.

BORGES, M. O golpe em Goiás: história de uma grande traição. Rio de Janeiro: Civilização Brasileira, 1965.

CAMPOS, F. I. Ciências sociais: os alunos constroem o curso. Disponível em: <http://xa.yimg.com/kq/ groups/19095426/1770657814/name/ENESCS+\%28Exe cutiva $+\mathrm{Nacional}+$ dos + Estudantes + de $+\mathrm{Ci} \% \mathrm{C} 3 \%$ A Ancias + Sociais.pdf 2008>.

ESTEVES, C. L. Homem certo para o lugar certo: colonização, educação rural e tecnização da agricultura na experiência dos combinados agrourbanos em Goiás durante o governo Mauro Borges Teixeira (1961-1964). In: Olinto, B. A.; MOTTA, M. M.; OliveirA, O. de (Orgs.). História agrária: propriedade e conflito. Paraná: Unicentro, 2008.

FERREIRA DE FREITAS, L. C. B. UFG: tempo de crescer. Disponível em: <http://projetos.extras.ufg.br/ capa/50anos/>. Acesso em: $1^{\circ}$ mar. 2015. 
LIMA, N. C. de; SOUZA, M. L. R. de; LAZARIN, M. A.; DUARTE CÂNDIDO, M. M. Um curso de Museologia para Goiás: Bacharelado em Museologia da UFG. Anais do I Congresso Internacional de Museologia: sociedade e desenvolvimento. Maringá: Ed. UEM, 2009. Disponível em: <http://www.cienciassociais.ufg.br/ uploads/106/original_2009__Artigo_Um_curso_de_ Museologia_para_Goi__s_-_Maring__.pdf>.

MARTINS, C. B. A Reforma Universitária de 1968 e a abertura para o ensino superior privado no Brasil. Educ. Soc., Campinas, v. 30, n. 106, p. 15-35, jan./abr. 2009. Disponível em: <http://www.cedes.unicamp.br>.

MOREYRA, S. P. Memória. Uma história de persistência: pioneiros contam parte da trajetória de luta e obstinação de quem ousou sonhar a UFG. UFG AFIRMATIVA, Publicação da Assessoria de Comunicação da Universidade Federal de Goiás, Edição novembro de 2008, p. 32-33. RABÊLO, F. C. E. Governo Mauro Borges: tradicionalismo, planejamento, e mobilização social em Goiás. Dissertação (Mestrado em Ciência Política) - Universidade Federal de Minas Gerais, Belo Horizonte, Minas Gerais, 1975.

TAVEIRA, E. L. de M. Museu Antropológico da UFG: criação e consolidação do Museu Antropológico/UFG, 2012. (No prelo).

SILVA, A. L. Carta enviada aos professores do IF em 24 de agosto de 2012. Disponível em: <http://www.greveufg. blogspot.com.br/2012/08/carta-aos-professores-por-analucia-da.html>.

\title{
Brief history of Social Sciences courses at the Federal University of Goiás (UFG)
}

\begin{abstract}
Briefly this article aims to present the history and development of Social Sciences undergraduate courses at the Federal University of Goiás (UFG), Brazil, from its creation to the present time. In order to write this paper, we interviewed professors of some long term career and also gathered reports and memories of others already retired who have dealt with the course of Social Sciences, as well as a documentary research.
\end{abstract}

Key words: memory, Social Science courses, UFG.

\section{Breve historia de los cursos de Ciencias Sociales en la Universidad Federal de Goiás (UFG)}

\section{Resumen}

Ese artículo tiene como objetivo presentar de forma breve la historia y el desarrollo de la Licenciatura en Ciencias Sociales en la Universidad Federal de Goiás, desde su creación hasta la actualidad. Para la elaboración del texto, los autores realizaron entrevistas a profesores con muchos años de carrera y recabaron informes y memorias de otros profesores acerca con especialización en Ciencias Sociales, además de la investigación documental.

Palabras clave: memoria, Licenciatura en Ciencias Sociales, UFG.

Data de recebimento do artigo: 30/10/2014

Data de aprovação do artigo: 18/12/2014 